be compulsory. Medical men should not be compelled to inform on their patients, but the state should co-operate with them in securing early treatment for tuberculosis.

Legislation must always be behind and not in advance of public opinion. Public health laws which seriously interfere with personal liberty ean only be enforced when an active public sentiment is behind them.

Dr. E. KLeBS-I quite agree with Dr. Moyer that we must have public sanatoria, but how many? In Chicago alone we would require 20,000 beds. It is not possib? to seclude all these patients - to take them away from their families, or the workshops or from the schools, but we must look to reducing this danger as much as possible. We must have physicians appointed to inspect schools; if a school inspector finds a child that expectorates an enormous quantity of tubercle bacilli each day, that child must be excluded from the school. The dissemination of tuberculosis in the workshop is another source; there should be an inspection of these people. If they can not be excluded, there must be means furnished by which the expectoration may be sterilized or destroyed. In tuberculosis, the state has very great duties to perform, and it is a matter for eareful consideration; radical measures, however, should not be resorted to.

Dr. A. R. ReYnolns--I have never been able to make myself believe that good could be arcomplished by insisting on exclusion of tuberculosis. I am of opinion that we already have law enough in the state to insist on tuberculosis being a notifiable disease, but I believe, with the essayist, that it would be a difficult matter to segregate patients. If a patient knows how to take care of himself, he need not be excluded. It is along this line that the laws must be shaped; the state can only help in disseminating this information. I think the public is well informed on these matters at the present time, considering that it is only a few years since the discovery was made; all understand that this is an infectious disease and are eager for information regarding protection against it.

I do not quite agree with Dr. Ingals in his assumption that patients do not wish to be told of their ailment, especially when I consider that 70 per cent. of his patients are consumptives. Although $\mathbf{l}$ have no reason to doubt his word, I can searcely conceive that so large a percentage would shrink from a knowledge of their trouble. It is for this reason that they consult physicians, and if it were not for the skill that physicians have in diagnosing disease, the calling would not be so much sought as it is. In the treatment of consumption they are not altogether suceessful. This subject can not be discussed too often nor published too widely.

Dr. Jos. MatTeson-I did not suppose that this was the popular side of this subject at the present time, judging from the extended discussion it is receiving and the number who seem to be in favor of excluding tuberculous patients. I have been gratified by the substantial concurrence of opinion expressed by the gentlemen who have discussed the paper this evening.

\section{TRAUMATIC PERFORATIONS OF THE MEMBRANA TYMPANI.*}

BY FRANCIS R. PACKARD, M.D.

Aurist to the Out-Patient Department of the Pennsylvania Hospital; Instructor in Laryngology in the University of Pennsylvania; Dean of the I'hiladelphia Polyclinic, Etc. PIIILADELPHIA.

In 1500 consecutive cases taken from the out-patient record books of the Pennsylvania Hospital there were eleven in which the membrana tympani was ruptured by traumatism. The cases were as follows:

CASE 1.-An Irishman, aged 46 years, a longshoreman, was struck on the head by a hammer weighing 3 pounds, which had fallen forty feet. He sustained a severe lacerated wound of the scalp and was rendered unconscious for some minutes. On recovering consciousness, he was deaf in the left ear and suffered: from much roaring noise in it. The left auditory canal con-

\footnotetext{
* Read before the Philadelphia County Medical Society, Dec. 13,
} 1893. tained considerable blood. There was a large laceration in the anterior lower segment of the left membrana tympani. At the end of three weeks' treatment his hearing was normal and he had no tinnitus.

CASE 2.-A longshoreman, five days previous to presenting himself at the dispensary, had fallen thirty feet, sustaining severe contusions of the head and shoulders. Ever since the accident there had been considerable bloody discharge from his left auditory meatus, and he had had much tinnitus in that ear and been totally deaf in it. Examination showed that while sound conduction through the external auditory canal was lost, bone conduction remained normal. There was a large perforation in the central portion of the left membrana tympani. This case pursued a very tedious course. Three months after the patient's first visit the discharge had ceased, but hearing was impaired and there was considerable tinnitus.

CASE 3.-A telegraph operator, aged 39 years, who one week before coming to the dispensary was poking in his left ear with a penholder, suddenly felt something give way and suffered a sharp pain and heard a roaring noise in his left ear, which at once became deaf. Next morning there was much bloody discharge. Examination showed his left external auditory canal full of bloody pus, and after careful cleaning a large ragged perforation was found in the lower posterior portion of the left membrana tympani. The handle of the malleus was fractured, the two fragments being bent on one another at an angle of $4 \tilde{5}$ degrees. This man recovered perfectly in six weeks, the discharge ceasing, tinnitus disappearing and his hearing becoming as sharp as ever. His right membrana tympani was perfectly normal.

CAsE 4.-An Italian musician, three weeks before pre. senting himself at the dispensary, had been struck by a very high sea-ware, while bathing in the surf. It knocked him down and when he arose and got out of the water, he found he was deaf in his left ear, and had much roaring and pain in it. The next day a bloody discharge made its appearance at the left external auditory meatus. Examination revealed a small amount of purulent discharge in the external auditory canal, and a linear, vertical perforation in the lower posterior segment of the membrana tympani. He remained under treatment for some weeks, and when last seen his discharge had stopped, but his hearing remained somewhat impaired, and he still had a slight amount of tinnitus.

CASE 5.- An Italian artist, who had received a blow on the left ear two days before coming to the dispensary, presented himself, complaining of deafness and roaring in the left ear. Examination revealed a considerable bloody muco-purulent discharge in the left external auditory meatus. On removing it, a large tear was visible across the center of the left membrana tympani. This man's discharge ceased in a few weeks, and his hearing was restored and the tinnitus checked.

CASE 6.-A married woman, aged 36 years, presented herself at the dispensary with a history of having received a blow on the left ear one week before. Since then she had been deaf in the left ear, and had had much tinnitus in it, andconsiderable bloody discharge. The left membrana tympani showed a large perforation, the definite location of which was not obtained at the first examination, and subsequently, through neglect, no note was made of it. 'This woman pursued' a good course to complete restoration of function and cessation of symptoms.

CASE \%.-A laborer presented himself complaining of 
pain, deafness and tinnitus in the left ear, from which there was considerable bloody discharge. He said that three days before, while working in a caisson these symptoms had suddenly presented themselves. Being a very unintelligent man, no more definite history could be obtained. There was a large perforation in the center of the membrana tympani. He recovered perfectly in a few weeks, except that when last seen he complained that he still had a sensation of fulness in his left ear.

Case 8.-A Russian carpenter had been struck on the head eight days before coming to the hospital. No history was obtained as to how or with what he had been struck. He complained of pain and deafness. The right external auditory meatus was full of bloody pus, and there was a large ragged perforation in the right membrana tympani, the exact location of which, however, was not noted. The man did well and was discharged as cured in a few weeks.

CASE 9.-An Italian laborer was struck on the left side of his head with the handle of a pitchfork, one week beforecoming to the hospital. From that time he complained of pain, deafness and roaring in his left ear. 'There was a small amount of bloody discharge and a round perforation just posterior to the central portion of the left membrana tympani. Within ten days the discharge had ceased and function was restored.

CASE 10.-An errand boy, sent to the out-patient department from the wards of the hospital, had one week before fallen down an elevator shaft and sustained many lacerated and contused wounds of the scalp. From this time he had pain in the left ear and some deafness and tinnitus. Some bloody purulent discharge was removed from his left external auditory meatus; after this a perforation in the anterior lower segment of the left membrana tympani became visible. Within ten days the discharge and other symptoms had ceased.

CASE 11.-A laborer came to the out-patient department with a history that a heavy bag of corn had dropped on his head four days previously. Since that time his right ear had been the seat of continuous roaring noises, much pain, and considerable discharge. $\mathrm{He}$ suffered much from vertigo. After cleansing a considerable quantity of dried blood from the right external auditory canal, a large ragged perforation was revealed in the anterior lower segment of the right membrana tympani. His left membrana tympani was very opaque and considerably retracted. After treatment for about six weeks he was discharged cured, with complete restoration of function.

As to the relative frequency of such lesions compared with other pathologic conditions of the ear, it will be readily seen, by reference to the figures I furnish, and to those given in many statistical articles on the subject, that their number is not very great; this in spite of the fact that the injury is such as to produce symptoms which stand in such immediate relation as to cause and effect, and possess such an alarming significance in the patient's mind as to prompt his early recourse to a physician for relief.

Randall, ${ }^{1}$ in a tabulation of 5412 cases of ear disease, found but five traumatic perforations of the ear drum.

Treitel $^{2} \mathrm{n} 831$ cases occurring in thirteen months in Professor Gottslein's clinic, found 18 of traumatic perforation.

Politzer $^{3}$ says that traumatic lesions of the drum may be produced: 1, by direct penetration of a foreign body into the membrana tympani; 2 , by the extension of a fracture of the cranial bones to the membrane; 3 , by a sudden condensation of air in the external meatus or in the tympanic cavity, more rarely by a rapid rarefaction of the external air. He gives the statistics compiled by Brigade Surgeon Chimani, from 5041 cases of ear trouble. Of these 54 were cases of traumatic perforation of the drum. They were caused in 38 cases by falls on the head, in 3 cases by a kick from a horse on the head, in 2 cases by strokes upon the head with wooden clubs, in 2 cases by the playing of brass instruments (signal trumpet and helicon), in 2 cases by the report of a loaded gun in the immediate neighborhood of the ear, and in 1 case by a fall into the water from a considerable height."

G. P. Field ${ }^{4}$ analyzed 400 perforations of the membrana tympani and found that eighty of them could be attributed to traumatism. In a number of instances the perforations were double, so that the number of cases does not correspond to the number of perforations.

As to the causes producing these traumatic perforations, he found them to be: Falls on the head, 11 perforations; other injuries to head, 30 ; boxing ears, 8; from other blows on head, 16 ; penholder in ear, 1 ; hairpin in ear, 1 ; foreign bodies in ear, 4 ; kick of a horse, 1 ; blows from cricket balls, 2 ; injury from football, 1 ; fall of flower pot on head, 1 ; violent sneezing, 2 ; pouring turpentine in ears, 2 ; pouring urine in ear, 1 ; syringing by a doctor, 1 ; scald of ear, 1 ; silver nitrate used by patient in ear, 1 .

The causes of the traumatic perforations in the cases I report were as follows: Struck by weight falling from a height, 2 ; fall upon head, 2 ; the result of introducing a foreign body, 1 ; struck by wave while bathing, 1 ; blow on ear-fist-2; working in caisson, 1 ; struck with weapon, 1 ; blow on head, but from what not ascertainable, 1 .

But one of the eases which I report was the result of direct penetration of the membrana tympani by the introduction of a foreign body. This was Case 2 who penetrated his drum with a penholder with which he was scratching his ear.

Sajous reports two cases from 'Turnbull's clinic, in which the perforation resulted from this cause. In one there was a fracture of the malleus similar to the one scen in mine, and appended to the article are references to cases of the same nature accompanied by a like fracture reported by Meniere, ${ }^{6}$ Politzer, ${ }^{7} \mathrm{R}$. F. Weir, ${ }^{8}$ and Hinton, ${ }^{9}$ with mention of a short notice of such a case with specimen in Tovnbee's collection, now in the Hunterian Museum of the College of Surgeons of Lundon.

Gorham Bacon ${ }^{1 ;}$ reports a case of perforation of the membrana tympani by the twig of a tree, which occurred in a man who was walking through some woods. $\mathrm{He}$ also ${ }^{11}$ reports two other cases, one due to puncture with a piece of stick, the other occurred whilst scratching the ear with a pin.

A. H. Nott'2 reports the case of a man whose left membrana tympani was ruptured by the penetration through it of an umbrella rib. The injury resulted in the entire loss of the sense of taste on the left side of his tongue.

A most interesting case from a medicolegal point of view is reported by $\mathrm{A}$. S. Barling. ${ }^{13} \mathrm{~A}$ man, while in a brawl, was stabbed in the right ear with a knife. The knife blade was so very thin that it caused no external wound, but produced an incised one of the membrana tympani, one-fifth of an inch long, just posterior to the handle of the malleus; this wound was only found after careful examination. There was considerable hemorrhage. At first a defense was made that no stabbing 
had been done, although the victim insisted that his assailant had a knife in his hand. Finally, after some interval of time, the knife was found near the scene of the assault, where it had been thrown away by the aggressor as soon as he had done the stabbing.

Urbautschitsch ${ }^{14}$ reports a case in which a man attempted suicide by shooting himself in the right temple. The bullet could be detected through the external auditory meatus in the tympanic cavity. It was extracted by chiseling away the surrounding bony structures.

A. M. Shield ${ }^{15}$ saw an interesting case in which molten lead had been splashed over the side of the patient's head and some had run into his right external auditory meatus, almost entirely filling his tympanic cavity, some even entering the Eustachian tube. The lead was removed by filling the ear with liquid mercury and allowing it to remain in the ear for sixteen hours, when the softened mass was easily syringed out.

Among other interesting cases of penetration of the membrana tympani by foreign bodies introduced through the external auditory canal may be mentioned those reported by Mandelstamn, ${ }^{16}$ Treitel, ${ }^{17}$ F. L. Jack, ${ }^{18}$ Barr, ${ }^{10}$ T'angeman, ${ }^{20}$ Praislen, ${ }^{21}$ L. S. Somers ${ }^{22}$ and A. H. R. Stewart. ${ }^{2 *}$

Oftentimes the drum is perforated during clumsy efforts at extraction, as in one of Bacon's cases, and not by the unaided impact of the foreign body.

Cases of rupture of the membrana tympani due to syringing the ear are not rare. Such cases are reported by $S$. I tatimer Phillips ${ }^{24}$ and Sexton. ${ }^{25}$

In all the above-mentioned the foreign body causing the perforation was introduced through the external auditory canal. Cases have been reported, however, in which the membrana tympani was perforated by a foreign body entering the tympanum through the Eustachian tube. P. Hoover ${ }^{26}$ reports such a case in a child 2 years old, who swallowed a pin, which subsequently emerged point first, through the membrana tympani. The child had been given an emetic, and it was probably forced into the Eustachian tube by the effort of vomiting. L. W. Reynolds ${ }^{2 i}$ reports a curious case occurring in a woman who was suffering from the vomiting of pregnancy, and in her expulsive efforts ejected a number of round worms from her mouth, nostrils and both ears. The drums were torn and free bleeding from both external auditory meati occurred.

None of the cases in the series I report were due to extension of a fracture of the cranial bones. Cases of this nature are reported by J. M. Ray, ${ }^{28}$ Gorham Bacon, ${ }^{29}$ Cornelius Williams, ${ }^{30} \mathrm{~J}$. D. Rushmore, ${ }^{31}$ Scheibe, ${ }^{32}$ A. Alt ${ }^{33}$ and R. Barclay. ${ }^{34}$

In the 11 cases which I report there were 4 patients with perforation of the membrana tympani due to the sudden condensation or rarefaction of air in the external auditory meatus, beyond a doubt. Three more could be with probability assigned to this cause. One of the latter had been struck on the side of the head by a bag of corn falling some distance, another had been struck in a quarrel, most likely by his opponent's fist, the third had received a blow directly over the ear from the blunt handle of a pitchfork. Of the 4 undoubted cases, 1 was the result of the impact of water, 1 resulted from working in a caisson, and 2 were the results of blows with the fist.

Probably the latter is the commonest cause of perforation due to sudden condensation of air in the external auditory meatus. In the cases which result from it the lesion is usually unilateral and found in the left membrana tympani, because the person who strikes does so with his right hand as a rule. In former days, when boxing the ears was a popular mamner of administering reproof in school, the number of cases of perforation resulting from this form of punishment is said to have been very large. One recalls the method of punishing school boys by boxing both sides of the head simultaneously with two books, referred to by Thackeray in his Roundabout Paper entitled "De Juventute." In Chimani's 38 cases of rupture of the ear drum due to blows with the fist, 36 were in the left ear, only two in the right.

Dalby $^{35}$ says that the injuries resulting from boxing ears are of three kinds: 1 . The hearing may be immediately damaged without injury to the membrana tympani, the loss of hearing being due to injury of nervous structures. 2. The membrana tympani may be ruptured, the perforations usually assuming the form of a vertical slit which, if left alone, heals in a few days, though occasionally suppuration is seen. 3. Without rupturing the membrana tympani an acute otitis media may occur, with possible ultimate perforation of the membrana tympani and loss of hearing.

Cases resulting from blows with the fist upon the ear are reported by C. R. Agnew, ${ }^{36}$ Dills, ${ }^{37}$ Core, ${ }^{38}$ Gorham Bacon, ${ }^{39}$ Treitel, ${ }^{40}$ H. Richards, ${ }^{41}$ W. H. R. Stewart, ${ }^{42}$ A. A. Hubbell, ${ }^{43}$ Fetterhoff, ${ }^{44}$ Braislin $^{45}$ and R. Barclay. $^{46}$ C. R. Agnew and D. Webster ${ }^{47}$ and A. H. Cheatle ${ }^{48}$ report cases of double perforation of the membrana tympani resulting from blows with the fist.

Cases of rupture of the tympanic membrane from the condensation of air produced by discharge of artillery or the explosion of powder are reported by Sexton, ${ }^{49}$ Bates, ${ }^{50}$ and C. C. Colles. ${ }^{51}$. C. H. Alden ${ }^{52}$ reports a case of repeated ruptures of the membrana tympani occurring in an artilleryman, finally resulting in total deafness, requiring his discharge from the service. Moos ${ }^{53}$ reports one of a chemist who was working with some chloraphthalic ether which exploded. Both of his membanæ tympani were ruptured as a consequence, and he developed a suppurative otitis media.

Cases of traumatic perforations of the membrana tympani as the result of working in caissons or diving bells have been reported by Moos, ${ }^{54}$ Sexton, ${ }^{55}$ G. E. Bellows. ${ }^{56}$

Two interesting cases of loss of hearing due to condensation of air in the external auditory canal, by the impact of water in diving, are reported by $\mathrm{H}$. Augustus Wilson. ${ }^{57}$

Of air pressure on the inner surface of the membrana tympani causing rupture, I have gathered three cases: A. G. Welsford ${ }^{53}$ reports a man who suffered from chronic bronchitis, and during a violent coughing spell ruptured both ear drums. S. I. Phillips ${ }^{\prime 59}$ patient with perforation due to syringing the ear, subsequently sustained another rupture of the same drum while blowing his nose. C. R. Agnew ${ }^{60}$ reports the case of a man who ruptured his left membrana tympani while blowing his nose. Agnew thinks there was undoubtedly pre-existing disease of the membrana tympani, but the man positively denied ever having noticed any previous trouble with his ear. F. D. Clark ${ }^{61}$ reports one in which a man was struck by lightning, sustaining burns of the left side of the head, the neck and breast. Some days after the accident the ear began discharging pus, and an examination revealed a perforation in the left membrana tympani. The auricle had not been injured in any way. The difficulty in this case lies in deciding whether concussion caused the perforation, or whether it was due to a burn produced by the lightning. The perforation 
healed, but the man remained deaf and suffered much from tinnitus. Ludewig ${ }^{\epsilon 2}$ reports a case in which the drum membrane was undoubtedly ruptured by the shock of the lightning bolt.

The location of the perforation in the drum membrane varies with the cause producing it. In those cases due to penetration by a foreign body, Politzer states that it is more frequently in the posterior than in the anterior portion of the drum; when due to extension of a fracture of the cranial bones, the perforation extends fissure-like from the superior or anterior wall of the meatus, and, if resulting from sudden condensation of air in the external auditory meatus, it presents itself as a gaping orifice, more frequently in the posterior portion of the membrane. 'T'reitel ${ }^{\mathbf{6 3}}$ carefully studied eighteen cases of traumatic perforation, in $\mathbf{1 1}$ of which the perforation was in the inferior half; of these, 8 were in the anterior inferior portion, and 3 in the posterior inferior portion, from which he concludes that the inferior and anterior portions constitutes the elected region. This statement agrees with Schwartze, but differs from Hassenstein, who considers a traumatic perforation in front of the malleus as very rare. Treitel makes the statement, which is now acceded to by most authorities, that rupture of the drum from sudden condensation of air can occur in the perfectly healthy drum and with a free Eustachian tube, but that it is more apt to occur in persons whose Eustachian tube is not perfectly patulous or who have ear drums which have been the site of previous pathologic changes. In Chimani's 38 cases of rupture due to boxes on the ear, 27 were in the posterior inferior quadrant, 9 in front of and below the malleus, 2 in the posterior superior portion of the membrane.

As to the ultimate termination of such injuries, if the perforation is uncomplicated with injury to the ossicles or labyrinth, the prognosis is good, the perforation usually healing. In Nott's case, which was followed by loss of taste on the injured side, there was evidently accompanying injury to the chorda tympani. All authorities agree that the best possible treatment is to leave the handling of the case to Nature as far as possible. In those I report a little clean, dry cotton was kept con-

- stantly in the external auditory meatus. and no attempt made to do anything beyond the gentlest possible cleansing in cases where there was much discharge. In Chimani's 38 cases of perforation due to boxing the ears, perfect recovery without functional disturbance occurred in 34 ; in 4 only complete cure was effected.

Cases of traumatic perforation of the drum present - several points of medicolegal importance: 1, to determine that the rupture is due to traumatism ; 2 , to determine the amount of permanent functional or organic damage wrought by the injury, if it exists.

In the 1500 cases from the books of the out-patient department of the Pennsylvania Hospital, there were 3 in which it was claimed that the patient's ear condition

- resulted from an injury. One was a man who claimed to have fallen from a trolley car. He had chronic suppurative inflammation of the ear, which, he said, had only begun to suppurate since the accident. That this was chronic was proved by the fact that the ossicles were necrosed, and, moreover, there was evidence of old mastoid trouble, notwithstanding the fact that the in-

- jury was said to have been sustained only a few days before his visit to the hospital. The other two cases in which injury was claimed were both school children, whose ears were said to have been boxed, but in whom areful examination and questioning elicited history of vious suppuration. Politzer savs that the most de- finite evidence of the traumatic origin of a perforation is its rapid cicatrization. The only way in which the amount of functional disturbance can be determined is by repeated careful tests of the hearing power by the usual methods employed for that purpose. Much care must be taken in these tests to detect simulated deafness, as in many of these cases the examination is required to determine the claims for damages of the patient. It must always be remembered that the amount of disturbance of hearing bears but little proportion to the amount of destruction of drum tissue. Patients are frequently seen in aural clinics who have suffered complete destruction of the drum and yet retain their hearing to a remarkable extent. In cases of traumatic perforation which are accompanied by Jabyrinthine involvement the amount of labyrinth mischief will be the chief guide as to the functional disturbance which the patient's organ of hearing has sustained.

I desire to express my thanks to Dr. George C. Harlan for his kindness in permitting me to avail myself of the records of the Pennsylvania Hospital.

\section{BIBL.YOGRAPHY.}

1. Annals of Ophthal. and Otol 1894 ifi

2. Transi. in Arch. of Otol., 1900, xix, 110.

3. Tiseages of the Fiar.

4. Med. Press and Cir., 1.886. xxx. \$5, 169.

Med. and Surg. Reporter, 1879, p. 161.

f. Gaz. Med. de Paris, 1856, Ne. 50.

8. Trans. Am. Otol. Soc., 1870.

9. Questions of Aural Surgery.

10. Trans. Am. Otol. Soc. 1882, iii, p. 541

11. N. Y. Med. Jour., 1887, XIv, 5is, and N. Y. Med. Rec., 1885

12. Indian Med. Gaz., 1893, xxviii. 13

. Brit. Med. Jour., 1897, li. 1180

14. Jour. of Laryng., Rhinol. and Otol., 1897, xil, 255.

5. Lancet, 1892, i, 970

16. Archives of Otology, 1891, xxi, 128

18. Transl. in Archi. of Otol., 1890, xix, 110

19. Boston Med. and Surg. Jour., 1891, cxxiv, 50

20. Edinburgh Med. Jour. 1887-88, xxxiii, 613

21. Cincin. Lancet and Cinic, 1885. Xv, 649

22. Prooklyn Med. Jour., 1898, xii,

23. Lancet, 1889 . 1, 574 .

24. Atlanta Med. and Surg. Jour., 1890-91. vil. .707.

26. The Ear and its Diseases.

26. N. Y Med. Jour., October 50, 1897

28. Archiv. of Otol., 1886. xv. 192

29. Loc. cit.

30. Arch. of Otol., 1884, xiil, 156

31. Arch. of Otol.. 1881, $\mathrm{x}, \mathbf{3 1 5}$.

32. Arch. of Otol.. 1897, xxvi, 400

3. Am. Jour. Ophth., 1884, 1, 39.

34. Med. and Surg. Reporter, 1894. xx, 158.

35. Brit. Med. Jour., 1882, ii, 1249

36. Med. Rec., 1880, xvili, 169

37. Archiv. of Otol., 1880, ix, 154 .

1-82. ii, 128.

39. N. Y. Med. Rec., 1885, Xxvil, 403; also N. Y. Med. Jour., 1887, , 513

Archiv. of Otol., 1890, xix, 110

41. Trans. Am. Otol. Soc., 1889, 477

42. Lancet, $1889, \mathrm{i}, \mathbf{5 7 4}$.

Buffalo $M$. and $\mathbf{S}$. Jour. 1888-80,

617. 45.

Brooklyn Med. Jour., 1898, xii. 9.

46. International Clinics, 1894, ili, 354, and General Practitioner 1896, ii, 11 .

7. Archiv. of Otol., 1881, $x, 339$

48. King's Coll. Hosp. Kep.. 1894-95, ii, 261

49. N. Y. Med. Rec., 1887, xxxi, 201.

50. N. Y. Med. Jour. 1892 , lq, 2

51. Am. Medico-Surgical Bulletin, 1896, x, 655

52. Rep. Surg.-Gen. of the Army, 1885-86, 87.

53. Archiv. of Otol., $1881, x, 100$

54. Archiv. of Otol., $1881, x, 100$.

55. N. Y. Med. Rec., 1887, xxxi. 732

56. Kansas City Med. Rec., 1890, vii, 150.

57. Med. News, 1882, xli, 173 .

58. Brit. Med. Jour., 1894 , ii, 68

59. Loc. eit.

60. Med. Rec., 1880, xviii. 169

61. Archiv. of Otol.. 1892 , xxi, 34

62. Archiv. f. Phreuhk, 1889-90, xxix, 237.

63. Transl. in Archiv. of Otol., 1890 , xix, 110

MANY HAVE a history of specific disease in early life, with no symptoms after the first two or three years following the initial lesion, and then are troubled in late life.-J. Nevins Hyde. 